\title{
Data Analysis for Surface Plate Calibration
}

Federal Manufacturing \& Technologies

R. N. Burton

KCP-613-5986

Published August 1997

$$
\begin{gathered}
\text { RECEIVED } \\
\text { AllF } 191997 \\
\text { OSTI }
\end{gathered}
$$

Approved for public release; distribution is unlimited.
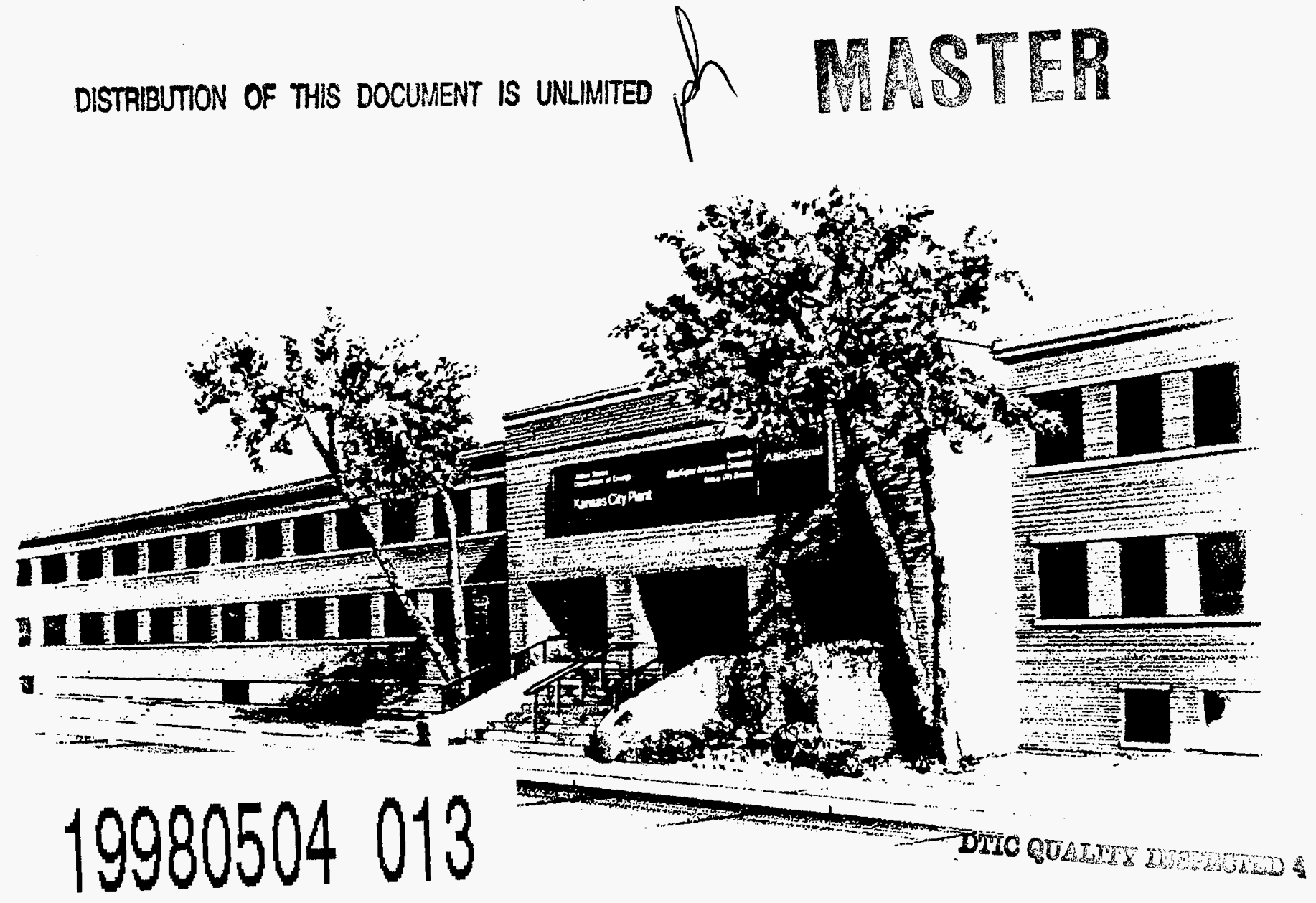

Prepared Under Contract Number DE-ACO4-76-DP00613 for the United States Department of Energy

AlliedSignal

A E R O S P A C 


\section{DISCLAIMER}

This report was prepared as an account of work sponsored by an agency of the United States Government. Neither the United States Government nor any agency thereof, nor any of their employees, makes any warranty, express or implied, or assumes any legal liability or responsibility for the accuracy, completeness, or usefulness of any information, apparatus, product, or process disclosed, or represents that its use would not infringe privately owned rights. Reference herein to any specific commercial product, process, or service by trade names, trademark, manufacturer, or otherwise, does not necessarily constitute or imply its endorsement, recommendation, or favoring by the United States Government or any agency thereof. The views and opinions of authors expressed herein do not necessarily state or reflect those of the United States Government or any agency thereof.

Printed in the United States of America.

This report has been reproduced from the best available copy.

Available to DOE and DOE contractors from the Office of Scientific and Technical Information, P. O. Box 62, Oak Ridge, Tennessee 37831; prices available from (615) 576-8401, FTS 626-8401.

Available to the public from the National Technical Information Service, U. S. Department of Commerce, 5285 Port Royal Rd., Springfield, Virginia 22161.

A prime contractor with the United States Department of Energy under Contract Number DE-ACO4-76-DP00613.
AlliedSignal Inc. Federal Manufacturing \& Technologies P. O. Box 419159 Kansas City, Missouri 64141-6159 
KCP-613-5986

Distribution Category UC-705

Approved for public release; distribution is unlimited.

\title{
DATA ANALYSIS FOR SURFACE PLATE CALIBRATION
}

\author{
R. N. Burton
}

Published August 1997

R. N. Burton, Project Leader 


\section{Contents}

Section

Page



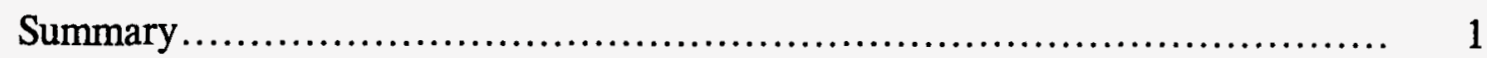

I. Introduction................................................................ 2

II. Moody's Method of Calibration ........................................... 3

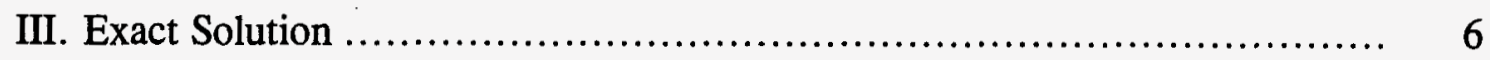

IV. Least Squares Solution ............................................... 15

V. Accomplishments ........................................................ 22

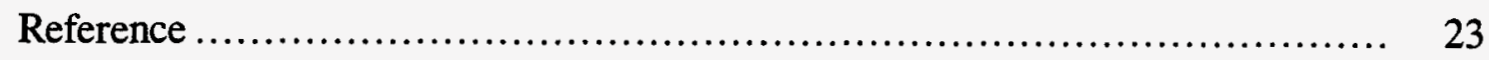




\section{Illustrations}

Figure $\quad$ Page

1 Top View of Typical Surface Plate Showing the Eight Lines of Readings Used in the Moody Method .......................................

2 Example Results Using Moody Method and Least Squares Method ......... 18

\section{Table}

Number

Page

1 Maximum Deviations in Millionths of an Inch for Ten Typical Plates .......

17 


\begin{abstract}
The currently accepted method of data analysis for surface plate calibration, the Moody method, does not give optimum results because of the arbitrary way in which the reference plane is chosen. The exact solution, wherein the reference plane is located in the optimum position, has been worked out and is given in a step-by-step procedure along with all of the necessary equations. The amount of calculation involved in a typical example proved to be prohibitive even for a computer, so an alternate solution using a least squares criterion for locating the reference plane was developed. Results were comparable with those from Moody's method with values being smaller or greater depending on the shape of the plate.
\end{abstract}

\title{
Summary
}

A surface plate is used to establish a reference plane used for making precision dimensional measurements. Ideally, the surface should be perfectly flat. Since it is impossible to create a perfectly flat surface, surface plates are calibrated to determine how much they deviate from a perfectly flat surface. Once a surface plate is calibrated, the user can determine if the plate is flat enough for use in a particular application.

When calibrating a surface plate, it is not possible to inspect every point on the surface, so a sampling technique is used. The profile is measured for a grid of eight lines over the surface of the plate. These eight profiles are mathematically combined to determine the flatness of the surface plate. The widely accepted method for taking the data and performing the analysis is known as the Moody method.

There is, however, an inherent shortcoming with this method. It does not guarantee optimum results. The ideal situation is to orient the position of a theoretical base plane, from which all the deviations are measured, so that the deviation of the point on the plate farthest from the plane will have the smallest value. The Moody method does not ensure that the plane will lie in this position.

This paper reports a mathematical procedure for determining the deviations from a plane located in the optimum location, using the same original data as the Moody method. Depending on the number of data points and the type of computer used to analyze the data, it may not be practical to implement this method. As an alternative, another method is also presented which uses the criterion of least squares to orient the reference plane. An example set of data is included which demonstrates the Moody method and the least squares method. 


\section{Introduction}

The basic goal in the calibration of a surface plate is to determine the deviations of its surface from a theoretical reference plane at a number of representative locations across the plate. A practical way for achieving this is by a method set forth by J. C. Moody of the Sandia Corporation, Albuquerque, New Mexico, in 1955. This method has been widely accepted over the years and has become the standard procedure for calibrations of this kind. A description of the method is given in Section II.

The advantages of the Moody method make it very attractive. It can be performed by semiskilled personnel using instruments available to any industrial laboratory, yet will yield accurate results.

There is, however, an inherent shortcoming in the method. It does not guarantee optimum results. The ideal situation is to orient the position of the theoretical base plane, from which all the deviations are measured, so that the deviation of the point on the plate farthest from the plane will have the smallest value. The Moody method does not ensure that the plane will always lie in this position. It has been found from a visual inspection of the final results of Moody's method in some cases that the maximum total deviation on the plates is $25 \%$ to $30 \%$ larger than would be if the theoretical reference plane were slightly tipped. These percentages could be larger if the plates are badly deformed. The ultimate disadvantage of reporting deviations that are too large is that it results in unnecessary lapping in order to bring the surfaces within specified limits. Valuable time can be saved by determining the true deviations, thus eliminating the need for extended lapping operations.

Consequently, an investigation was initiated to set up a mathematical procedure for determining the deviations from a plane located in the optimum location, using the same original data as in the Moody method. The results of that investigation are presented in this report. Section III gives the equations for the exact solution where the reference plane is in the optimum position. Section IV presents an alternate solution where the criterion of least squares is used to locate the reference plane.

Acknowledgment:

This paper is based on previously unpublished work by a former AlliedSignal engineer, Stan Drake (now deceased). 


\section{Moody's Method of Calibration}

A complete detailed description of the Moody method is beyond the scope of this paper, but enough of the basic concepts of the method will be presented to enable the reader to understand the difference between it, the exact solution, and the least squares solution. The entire method is presented in full in the October 1955 issue of The Tool Engineer in an article entitled "How to Calibrate Surface Plates in the Plant" by J. C. Moody.

Figure 1 is a top view of the typical surface plate under consideration. A total of eight lines of readings is taken: four perimeter lines, two diagonal lines, and two center lines. Moody refers to these lines using the words North, South, etc., but for convenience they will be identified throughout the remainder of this paper by the letters a, b, c, etc., as shown in Figure 1.



Figure 1. Top View of Typical Surface Plate Showing the Eight Lines of Readings Used in the Moody Method 
The data is typically taken using an autocollimator, a stationary mirror, a traveling mirror, and a straight edge. Alternatively, the data could be taken using an angular measuring laser interferometer, electronic levels, or any other high resolution angular measuring instrument. For the purpose of discussion in this paper, the use of an autocollimator will be assumed.

To "shoot" the "c" line, for example, the autocollimator is placed in the southwest corner, aimed at the northeast corner where the stationary mirror is located, and the traveling mirror is then moved progressively along the " $\mathrm{c}$ " line in steps equal to the distance between its feet. It is moved in the direction shown, the straight edge being used to guide the traveling mirror in a straight line. The entire optical system is adjusted so that the parallel rays of light emitted by the autocollimator are reflected back into the autocollimator from the traveling mirror. The reflected rays produce an image at the focal plane of the autocollimator from which angular displacements can be accurately determined. All autocollimator readings are recorded in arc seconds in relation to the line of first reading for the line in question.

The spacing between the feet of the base of the traveling mirror is selected in accordance with the size of the plate width. A satisfactory rule is to let this spacing, $M$, in inches be equal to the plate width in feet. For example, on a 3-foot wide plate, $M=3$ inches would be used.

The eight lines are laid out so that they are all an integral number of these $M$ increments in length and with the perimeter lines approximately $M$ inches in from the edges. In addition, the number of station points must be odd so that the intersections will not lie between station points. In attempting to satisfy all these requirements, difficulty is often encountered on the diagonals. Except for special cases, it is not possible to have an integral number of increments on a diagonal and at the same time have an integral number on the perimeter lines. (This can be achieved, for example, if the shape of the plate results in 3:4:5 triangles in each quadrant of the plate.) Moody does not offer a rigorous solution to this problem in his method. The perimeter lines are made exactly an integer number of $M$ increments long. On the diagonals then, the station points are laid out from the center, resulting in the last increment typically being a length other than $M$. This inequality of increments should be accounted for in the analysis; however, Moody ignores the inequality on the grounds that the resultant error is small. His analysis assumes that the station points on the diagonals are all equally spaced $M$ inches apart, including the end increments. In the exact solution given in Section III, odd length intervals are not ignored but are taken into account mathematically. 
Because of the geometrical configuration of the eight lines, it is not possible to shoot all these lines with the autocollimator in one position. In fact, the autocollimator has to be repositioned for each line. As a result, there is no common reference for all the numbers and each line of data is independent of the others. Since the lines are coincident at the intersections, it is obvious that the data must be made to tie together.

Moody proceeds in the following manner. A line of data may be tilted or translated as long as the relative shape of the line is not altered. This allows the formation of a net of connected lines. Line " $b$ " is adjusted so that its center point coincides with the center point on line "a." Since only two points are needed to establish the position of a line, the four perimeter lines may now be adjusted so that their end points coincide with the end points of the diagonals. The center lines now present a problem because they must pass through three points. If none of the readings contained error, this could be achieved. But in general, the readings will all contain some error so that the centerlines will appear warped relative to the others and will not close. Moody makes the centerlines coincide with the others at the center point and then rotates the centerlines until the error of closure is the same on both ends.

This approach is somewhat satisfactory except Moody completely ignores this error of closure in this analysis. He states that it is to be used as a criterion of accuracy in performing the calibration and that if it is below a certain value it may be disregarded. Otherwise the test must be repeated. However, this still gives two values for the station points at the ends of the center lines. Moody chooses the values from the perimeter lines and disregards those from the centerlines. From a practical viewpoint this is satisfactory, but for a mathematically rigorous solution, this error of closure must be taken into account. The exact solution in Section III does this by distributing the error back over the lines in proportion to the distance along the line.

The key difference between the Moody method and the exact solution in Section III is the location of the reference plane. In the Moody method, the plane is located as outlined below. The "a" line is tipped until the end values are the same. The center point on the " $b$ " line is then shifted to coincide with the center point on the "a" line. At the same time the " $b$ " line is tipped until the end values are equal. A pair of parallel planes may now be visualized in space, one through the end points of the "a" line and the other through the end points of the " $b$ " line. The desired reference plane is parallel to this pair of planes. The exact vertical location of the plane is through the lowest point so that all values are positive, but this feature has no bearing on the final shape of the surface.

It is obvious then that the orientation of the reference plane in the Moody method is not selected to achieve optimum results since it is always determined by the end points of the diagonals. The use of the diagonal end points rather than some other points is purely an arbitrary selection based mostly on convenience. The exact solution of Section III makes no such arbitrary selection. The points through which the plane will pass may be on any of the lines, depending on the data from that particular plate. 


\section{Exact Solution}

In the exact solution, the same original eight lines of readings are used that are used in the Moody method. The basic approach is to first establish an $\mathrm{x}, \mathrm{y}, \mathrm{z}$ coordinate for all station points and then using these data locate a pair of parallel planes enclosing all points such that the perpendicular distance between the planes is a minimum. The desired maximum deviation for the plate is then this minimum perpendicular distance. For convenience in the discussion, the configuration may be thought of as containing a single plane with perpendicular distances to it from all other points. There will be an optimum position for this single plane in which the maximum deviation or distance to the furthermost point will be a minimum. This is the same distance as in the parallel plane concept.

The calculation of the $\mathrm{x}, \mathrm{y}, \mathrm{z}$ coordinates cannot be undertaken unless all the lines close on each other. Since in general they will not close because of errors in the measurements, some scheme of closure must be devised wherein the data is adjusted. Many plans could be suggested, but the one chosen is as follows. Line "a" is left unaltered. Line " $\mathrm{b}$ " is adjusted so that its center point coincides with the center point on line "a." The perimeter lines are laid in so that their end points coincide with the end points of the diagonals. The ends of the centerlines are then adjusted to coincide with the center points on the perimeter lines. This results in the error of closure occurring at the center of the plate. There will be four separate height values at this point, two different ones from the center lines and two identical ones from the diagonal lines. The final value used for this point is the average of all four. Each of the four lines is then adjusted to this level at this point with a proportionate adjustment being made on all points from the center out to the ends. No error of closure adjustment is made on the perimeter lines.

With the data closed, the $\mathrm{x}, \mathrm{y}, \mathrm{z}$ coordinates may be calculated. It remains, then, to find the location of the optimum plane through these data.

It can be shown that the optimum plane, which is the one giving the smallest value for the maximum deviation on the plate, will pass directly through some of the coordinate points rather than between them as in a least squares type of fit. Consider an "optimum" plane passing between the points. In this case, a pair of planes parallel to this optimum plane could be constructed so that one passes through the uppermost point and one through the lowermost point, the perpendicular distance between them being the desired optimum deviation on the plate. The situation is then one of having two parallel planes defined by only two points. But since it takes more than two points to define a pair of parallel planes, these planes may be rotated about these two points until either three points lie in one plane or two lie in each plane. There will be a number of possible positions that the planes may finally take, but among this number there will always be some that put the planes closer together. Thus, a plane passing between the points will not necessarily yield the optimum deviation. 
Since the optimum plane must pass through some of the coordinate points, the optimum location is found by examining all possible positions and selecting the one giving the smallest value for the maximum deviation. The search is done in two parts. First, a plane is passed through all possible combinations of three points and the perpendicular distances to all other points for all combinations calculated. Second, a pair of parallel planes passed through all possible combinations of two pairs of points and perpendiculars from both planes to all points again calculated. In each combination from the complete search, there will be a maximum perpendicular distance. The desired answer will be the smallest of these maximum values.

The step-by-step procedure for calculating the exact solution will now be given. Let $\mathrm{A}$ represent the autocollimator readings in arc seconds and $i$ the particular station point in question.

Step 1. Compute "S" values for all station points on all lines from the raw data using the following equations:

$$
\begin{aligned}
& S_{1}=0 \\
& S_{2}=0 \\
& S_{i}=A_{2}(2-i)+\sum_{3}^{i} A
\end{aligned}
$$

There will be eight sets of " $S$ " values, one for each line. The values for the first two station points will always be zero.

Step 2. Compute a preliminary $\mathrm{X}, \mathrm{Y}, \mathrm{Z}$ coordinate for all station points on line a except the end and mid-points using the following equations:

$$
\begin{aligned}
& \mathrm{X}_{\mathrm{ai}}=\frac{\mathrm{L}}{2}-\frac{\mathrm{M}\left(\mathrm{n}_{\mathrm{c}}-1\right)\left(\mathrm{n}_{\mathrm{c}}+1-2 \mathrm{i}\right)}{2 \sqrt{\left(\mathrm{n}_{\mathrm{d}}-1\right)^{2}+\left(\mathrm{n}_{\mathrm{c}}-1\right)^{2}}} \\
& \mathrm{Y}_{\mathrm{ai}}=\frac{\mathrm{W}}{2}+\frac{\mathrm{M}\left(\mathrm{n}_{\mathrm{d}}-1\right)\left(\mathrm{n}_{\mathrm{d}}+1-2 \mathrm{i}\right)}{2^{\sqrt{\left(\mathrm{n}_{\mathrm{d}}-1\right)^{2}+\left(\mathrm{n}_{\mathrm{c}}-1\right)^{2}}}} \\
& \mathrm{Z}_{\mathrm{ai}}=\mathrm{K}\left[\mathrm{S}_{\mathrm{i}}+2\left(\frac{\mathrm{i}-1}{\mathrm{n}_{\mathrm{a}}-1}\right) \Delta \mathrm{a}\right] \quad 1^{\text {st }} \text { half line }
\end{aligned}
$$




$$
\begin{aligned}
\mathrm{Z}_{\mathrm{ai}}= & \mathrm{K}\left[\mathrm{S}_{\mathrm{i}}+2\left(\frac{\mathrm{n}_{\mathrm{a}}-\mathrm{i}}{\mathrm{n}_{\mathrm{a}}-1}\right) \Delta \mathrm{a}\right] \quad 2^{\text {nd }} \text { half line } \\
\Delta \mathrm{a}= & -1 / 4 \mathrm{~S}_{\mathrm{ar}}+1 / 8 \mathrm{~S}_{\mathrm{an}}-1 / 4 \mathrm{~S}_{\mathrm{br}}+1 / 8 \mathrm{~S}_{\mathrm{bn}} \\
& +1 / 8 \mathrm{~S}_{\mathrm{cr}}-1 / 16 \mathrm{~S}_{\mathrm{cn}}+1 / 8 \mathrm{~S}_{\mathrm{dr}}-1 / 16 \mathrm{~S}_{\mathrm{dn}} \\
& +1 / 8 \mathrm{~S}_{\mathrm{er}}-1 / 16 \mathrm{~S}_{\mathrm{en}}+1 / 8 \mathrm{~S}_{\mathrm{fr}}-1 / 16 \mathrm{~S}_{\mathrm{fn}} \\
& +1 / 4 \mathrm{~S}_{\mathrm{gr}}-1 / 8 \mathrm{~S}_{\mathrm{gn}}+1 / 4 \mathrm{~S}_{\mathrm{hr}}-1 / 8 \mathrm{~S}_{\mathrm{hn}}
\end{aligned}
$$

Where $L$ and $W$ are the length and width of the surface plate, respectively, $n_{a}$ is the number of station points on lines $a$ and $b, n_{c}$ is the number of station points on lines $c$, $e$, and $g, n_{d}$ is the number of station points on lines $d, f$, and $h, K$ is equal to $.00000048481 \mathrm{M}, \mathrm{r}$ refers to the value at the mid station point, and $\mathrm{n}$ refers to the value at the last station point.

Step 3. Repeat Step 2 for line b using the following equations:

$$
\begin{aligned}
& \mathrm{X}_{\mathrm{bi}}=\frac{\mathrm{L}}{2}+\frac{\mathrm{M}\left(\mathrm{n}_{\mathrm{c}}-1\right)\left(\mathrm{n}_{2}+1-2 \mathrm{i}\right)}{2^{\left(\mathrm{n}_{\mathrm{d}}-1\right)^{2}+\left(\mathrm{n}_{\mathrm{c}}-1\right)^{2}}} \\
& \mathrm{Y}_{\mathrm{bi}}=\mathrm{Y}_{\mathrm{ai}} \\
& \mathrm{Z}_{\mathrm{bi}}=\mathrm{K}\left[\mathrm{S}_{\mathrm{i}}+2\left(\mathrm{~S}_{\mathrm{ar}}-\mathrm{S}_{\mathrm{br}}\left(\frac{\mathrm{i}-1}{\mathrm{n}_{\mathrm{a}}-1}\right)+2\left(\frac{\mathrm{i}-1}{\mathrm{n}_{\mathrm{a}}-1}\right) \Delta \mathrm{a}\right. \text { half line }\right. \\
& \mathrm{Z}_{\mathrm{bi}}=\mathrm{K}\left[\mathrm{S}_{\mathrm{i}}+2\left(\mathrm{~S}_{\mathrm{ar}}-\mathrm{S}_{\mathrm{br}}\left(\frac{\mathrm{i}-1}{\mathrm{n}_{\mathrm{a}}-1}\right)+2\left(\frac{\mathrm{n}_{\mathrm{a}}-\mathrm{i}}{\mathrm{n}_{\mathrm{a}}-1}\right) \Delta \mathrm{a}\right]\right. \\
& 2^{\text {nd half line }}
\end{aligned}
$$

where $\Delta \mathrm{a}$ is given by equation (8).

Step 4. Calculate a preliminary $\mathrm{X}, \mathrm{Y}, \mathrm{Z}$ for all station points on line $\mathrm{c}$ using the following equations: 


$$
\begin{aligned}
& X_{\mathrm{ci}}=\frac{\mathrm{L}}{2}-\frac{\mathrm{M}}{2}\left(\mathrm{n}_{\mathrm{c}}-1\right)+\mathrm{M}\left(\mathrm{n}_{\mathrm{c}}-\mathrm{i}\right) \\
& \mathrm{Y}_{\mathrm{ci}}=\frac{\mathrm{W}}{2}+\frac{\mathrm{M}}{2}\left(\mathrm{n}_{\mathrm{d}}-1\right) \\
& \mathrm{Z}_{\mathrm{ci}}=\mathrm{K}\left[\mathrm{S}_{\mathrm{i}}-\mathrm{S}_{\mathrm{cn}}\left(\frac{\mathrm{i}-1}{\mathrm{n}_{\mathrm{c}}-1}\right)\right]
\end{aligned}
$$

Step 5. Repeat Step 2 for line d using:

$$
\begin{aligned}
& X_{d i}=\frac{L}{2}+\frac{M}{2}\left(n_{c}-1\right) \\
& Y_{d i}=\frac{W}{2}-\frac{M}{2}\left(n_{d}-1\right)+M\left(n_{d}-i\right) \\
& Z_{d i}=K\left[S_{i}+\left(S_{a n}-S_{d n}\right)\left(\frac{i-1}{n_{d}-1}\right)\right]
\end{aligned}
$$

$\underline{\text { Step 6. }}$ Repeat Step 4 for line e using:

$$
\begin{aligned}
& \mathrm{X}_{\mathrm{ei}}=\mathrm{X}_{\mathrm{ci}} \\
& \mathrm{Y}_{\mathrm{ei}}=\frac{\mathrm{W}}{2}-\frac{\mathrm{M}}{2}\left(\mathrm{n}_{\mathrm{d}}-1\right) \\
& \mathrm{Z}_{\mathrm{ei}}=\mathrm{K}\left[\mathrm{S}_{\mathrm{i}}+\mathrm{S}_{\mathrm{an}}+\left(\mathrm{S}_{\mathrm{bn}}+2 \mathrm{~S}_{\mathrm{ar}}-2 \mathrm{~S}_{\mathrm{br}}-\mathrm{S}_{\mathrm{an}}-S_{\mathrm{en}}\right)\left(\frac{\mathrm{i}-1}{\mathrm{n}_{\mathrm{c}}-1}\right)\right]
\end{aligned}
$$

$\underline{\text { Step } 7 .}$ Repeat Step 2 for line f using:

$$
\begin{aligned}
& \mathrm{X}_{\mathrm{fi}}=\frac{\mathrm{L}}{2}-\frac{\mathrm{M}}{2}\left(\mathrm{n}_{\mathrm{c}}-1\right) \\
& \mathrm{Y}_{\mathrm{fi}}=\mathrm{Y}_{\mathrm{di}} \\
& \mathrm{Z}_{\mathrm{fi}}=\mathrm{K}\left[\mathrm{S}_{\mathrm{i}}+\left(\mathrm{S}_{\mathrm{bn}}+2 \mathrm{~S}_{\mathrm{ar}}-2 \mathrm{~S}_{\mathrm{br}}-\mathrm{S}_{\mathrm{fn}}\left(\frac{\mathrm{i}-1}{\mathrm{n}_{\mathrm{d}}-1}\right)\right]\right.
\end{aligned}
$$


Step 8. Repeat Step 4 for line g using:

$$
\begin{aligned}
& \mathrm{X}_{\mathrm{gi}}=\mathrm{X}_{\mathrm{ci}} \\
& \mathrm{Y}_{\mathrm{gi}}=\frac{\mathrm{W}}{2} \\
& Z_{\mathrm{gi}}=\mathrm{K}\left[\mathrm{S}_{\mathrm{i}}+\mathrm{S}_{\mathrm{dr}}+1 / 2 \mathrm{~S}_{\mathrm{an}}-1 / 2 \mathrm{~S}_{\mathrm{dn}}+\left(\mathrm{S}_{\mathrm{fr}}+1 / 2 \mathrm{~S}_{\mathrm{bn}}+\mathrm{S}_{\mathrm{ar}}\right.\right. \\
& \left.-S_{b r}-1 / 2 S_{f n}-S_{d r}-1 / 2 S_{a n}+1 / 2 S_{d n}-S_{g n}\right) \\
& \left.\left(\frac{i-1}{n_{c}-1}\right)+2\left(\frac{i-1}{n_{c}-1}\right) \Delta g\right] \\
& 1^{\text {st }} \text { half line } \\
& Z_{g i}=K\left[S_{i}+S_{d r}+1 / 2 S_{a n}-1 / 2 S_{d n}+\left(S_{f r}+1 / 2 S_{b n}+S_{a r}\right.\right. \\
& \left.-S_{b r}-1 / 2 S_{f n}-S_{d r}-1 / 2 S_{a n}+1 / 2 S_{d n}-S_{g n}\right) \\
& \left.\left(\frac{i-1}{n_{c}-1}\right)+2\left(\frac{n_{c}-i}{n_{c}-1}\right) \Delta g\right] \quad 2^{\text {nd }} \text { half line } \\
& \Delta g \quad=1 / 4 S_{a r}-1 / 8 S_{a n}+1 / 4 S_{b r}-1 / 8 S_{b n}+1 / 8 S_{c r}-1 / 16 S_{c n} \\
& -3 / 8 \mathrm{~S}_{\mathrm{dr}}+3 / 16 \mathrm{~S}_{\mathrm{dn}}+1 / 8 \mathrm{~S}_{\mathrm{er}}-1 / 16 \mathrm{~S}_{\mathrm{en}}-3 / 8 \mathrm{~S}_{\mathrm{fr}} \\
& +3 / 16 \mathrm{~S}_{\mathrm{fn}}-3 / 4 \mathrm{~S}_{\mathrm{gr}}+3 / 8 \mathrm{~S}_{\mathrm{gn}}+1 / 4 \mathrm{~S}_{\mathrm{hr}}-1 / 8 \mathrm{~S}_{\mathrm{hn}}
\end{aligned}
$$

Step 9. Repeat Step 2 for line h using:

$$
\begin{aligned}
& \mathrm{X}_{\mathrm{hi}}= \frac{\mathrm{L}}{2} \\
& \mathrm{Y}_{\mathrm{hi}}= \mathrm{Y}_{\mathrm{di}} \\
& \mathrm{Z}_{\mathrm{hi}}=\mathrm{K}\left[\mathrm{S}_{\mathrm{i}}+\mathrm{S}_{\mathrm{cr}}-1 / 2 \mathrm{~S}_{\mathrm{cn}}+\left(\mathrm{S}_{\mathrm{er}}+1 / 2 \mathrm{~S}_{\mathrm{bn}}+\mathrm{S}_{\mathrm{ar}}-\mathrm{S}_{\mathrm{br}}\right.\right. \\
&\left.\quad+1 / 2 S_{\mathrm{an}}-1 / 2 \mathrm{~S}_{\mathrm{en}}-\mathrm{S}_{\mathrm{cr}}+1 / 2 \mathrm{~S}_{\mathrm{cn}}-\mathrm{S}_{\mathrm{hn}}\right) \\
&\left.\left(\frac{\mathrm{i}-1}{\mathrm{n}_{\mathrm{d}}-1}\right)+2\left(\frac{\mathrm{i}-1}{\mathrm{n}_{\mathrm{d}}-1}\right) \Delta \mathrm{h}\right] \quad 1^{\mathrm{st}} \text { half line }
\end{aligned}
$$




$$
\begin{aligned}
& Z_{\mathrm{hi}}=\mathrm{K}\left[\mathrm{S}_{\mathrm{i}}+\mathrm{S}_{\mathrm{cr}}-1 / 2 \mathrm{~S}_{\mathrm{cn}}+\left(\mathrm{S}_{\mathrm{er}}+1 / 2 \mathrm{~S}_{\mathrm{bn}}+\mathrm{S}_{\mathrm{ar}}-\mathrm{S}_{\mathrm{br}}\right.\right. \\
& \left.+1 / 2 S_{\mathrm{an}}-1 / 2 \mathrm{~S}_{\mathrm{en}}-\mathrm{S}_{\mathrm{cr}}+1 / 2 \mathrm{~S}_{\mathrm{cn}}-\mathrm{S}_{\mathrm{hn}}\right) \\
& \left.\left(\frac{i-1}{n_{d}-1}\right)+2\left(\frac{n_{d}-i}{n_{d}-1}\right) \Delta h\right] \quad 2 \text { nd half line } \\
& \Delta \mathrm{h}=1 / 4 \mathrm{~S}_{\mathrm{ar}}-1 / 8 \mathrm{~S}_{\mathrm{an}}+1 / 4 \mathrm{~S}_{\mathrm{br}}-1 / 8 \mathrm{~S}_{\mathrm{bn}}-3 / 8 \mathrm{~S}_{\mathrm{cr}}+3 / 16 \mathrm{~S}_{\mathrm{cn}} \\
& +1 / 8 \mathrm{~S}_{\mathrm{dr}}-1 / 16 \mathrm{~S}_{\mathrm{dn}}-3 / 8 \mathrm{~S}_{\mathrm{er}}+3 / 16 \mathrm{~S}_{\mathrm{en}}+1 / 8 \mathrm{~S}_{\mathrm{fr}} \\
& -1 / 16 \mathrm{~S}_{\mathrm{fn}}+1 / 4 \mathrm{~S}_{\mathrm{gr}}-1 / 8 \mathrm{~S}_{\mathrm{gn}}-3 / 4 \mathrm{~S}_{\mathrm{hr}}+3 / 8 \mathrm{~S}_{\mathrm{hn}}
\end{aligned}
$$

Step 10. Using the $X, Y, Z$ coordinates calculated in Steps 2 through 9, a final set of $\mathrm{x}, \mathrm{y}, \mathrm{z}$ coordinates is now calculated for all lines from the following equations:

$$
\begin{aligned}
& \mathrm{x}_{\mathrm{i}}=1 / 25\left(16 \mathrm{X}_{\mathrm{i}}+12 \mathrm{Y}_{\mathrm{i}}-15 \mathrm{Z}_{\mathrm{i}}\right) \\
& \mathrm{y}_{\mathrm{i}}=1 / 125\left(-24 \mathrm{X}_{\mathrm{i}}+107 \mathrm{Y}_{\mathrm{i}}+60 \mathrm{Z}_{\mathrm{i}}\right) \\
& \mathrm{z}_{\mathrm{i}}=1 / 125\left(93 \mathrm{X}_{\mathrm{i}}-24 \mathrm{Y}_{\mathrm{i}}+80 \mathrm{Z}_{\mathrm{i}}\right)
\end{aligned}
$$

Step 11. There will be a total of $\mathrm{N}$ station points on the plate where

$$
\mathrm{N}=2 \mathrm{n}_{\mathrm{a}}+3 \mathrm{n}_{\mathrm{c}}+3 \mathrm{n}_{\mathrm{d}}-15
$$

From all $N$ points, arbitrarily select three points, $P_{1}\left(x_{1} y_{1} z_{1}\right), P_{2}\left(x_{2} y_{2} z_{2}\right), P_{3}\left(x_{3} y_{3} z_{3}\right)$, and calculate the coefficients $\mathrm{j}, \mathrm{k}, l$ from: 


$$
\begin{aligned}
& j=\frac{\left|\begin{array}{lll}
x_{1} & 1 & z_{1} \\
x_{2} & 1 & z_{2} \\
x_{3} & 1 & z_{3}
\end{array}\right|}{\left|\begin{array}{lll}
y_{1} & z_{1} & 1 \\
y_{2} & z_{2} & 1 \\
y_{3} & z_{3} & 1
\end{array}\right|}(39) \\
& k= \\
& \left|\begin{array}{lll}
x_{1} & y_{1} & 1 \\
x_{2} & y_{2} & 1 \\
x_{3} & y_{3} & 1
\end{array}\right| \\
& \left|\begin{array}{lll}
y_{1} & z_{1} & 1 \\
y_{2} & z_{2} & 1 \\
y_{3} & z_{3} & 1
\end{array}\right|
\end{aligned}
$$

Step 12. From all remaining station points, calculate the perpendicular distances $u_{i}$ using the following equation:

$$
\mathrm{u}_{\mathrm{i}}=\frac{\mathrm{x}_{\mathrm{i}}+\mathrm{jy}_{\mathrm{i}}+\mathrm{kz}_{\mathrm{i}}+l}{\sqrt{1+\mathrm{j}^{2}+\mathrm{k}^{2}}}
$$

where $\mathrm{j}, \mathrm{k}, \mathrm{l}$ are from Step 11 and $\mathrm{i}$ is a particular station point from the total group of $\mathrm{N}$ rather than from a single line.

Step 13. Search the tabulation of $\mathrm{u}$-values from Step 12 and, if both plus and minus values are present, discard the entire set of calculations from Steps 11 and 12. If all values have the same sign, either plus or minus, retain the set and tabulate the maximum value. 
Step 14. Repeat Steps 11 through 13 for all other combinations of the station points taken three at a time. There will result a separate tabulation of maximum values from the few combinations having signs that are either all plus or all minus.

Step 15. The second survey is now started by arbitrarily selecting two points, $P_{1}\left(x_{1} y_{1} z_{1}\right), P_{2}\left(x_{2} y_{2} z_{2}\right)$, from the $N$ total. Another pair, $P_{3}\left(x_{3} y_{3} z_{3}\right), P_{4}\left(x_{4} y_{4} z_{4}\right)$, is chosen and the following criteria calculated:

$$
\begin{aligned}
& R 1=\frac{z_{1}-z_{2}}{x_{1}-x_{2}}-\frac{z_{3}-z_{4}}{x_{3}-x_{4}} \\
& R 2=\frac{y_{1}-y_{2}}{x_{1}-x_{2}}-\frac{y_{3}-y_{4}}{x_{3}-x_{4}} \\
& R 3=\frac{z_{1}-z_{2}}{y_{1}-y_{2}}-\frac{z_{3}-z_{4}}{y_{3}-y_{4}}
\end{aligned}
$$

If $R_{1}=R_{2}=R_{3}=0$, discard the pair $P_{3}, P_{4}$. If any one of the $R s$ is not zero, calculate the following constants:

$$
\begin{aligned}
& B=\frac{\left(x_{3}-x_{4}\right)\left(z_{2}-z_{1}\right)-\left(x_{1}-x_{2}\right)\left(z_{4}-z_{3}\right)}{\left(y_{1}-y_{2}\right)\left(z_{4}-z_{3}\right)-\left(y_{3}-y_{4}\right)\left(z_{2}-z_{1}\right)} \\
& C=\frac{\left(x_{1}-x_{2}\right)+B\left(y_{1}-y_{2}\right)}{\left(z_{2}-z_{1}\right)} \\
& D=\frac{z_{1} x_{2}-z_{2} x_{1}+B\left(z_{1} y_{2}-y_{1} z_{2}\right)}{\left(z_{2}-z_{1}\right)}
\end{aligned}
$$

These constants define a plane through $P_{1} P_{2}$ that is parallel to a plane through $P_{3} P_{4}$.

Step 16. The perpendicular distances $u_{i}$ from the $P_{1} P_{2}$ plane to all station points on the plate are now found from

$$
u_{i}=\frac{x_{i}+B y_{i}+C z_{i}+D}{\sqrt{1+B^{2}+C^{2}}}
$$

where the constants B,C,D are from Step 15. Repeat Step 13.

Step 17. Retain points $\mathrm{P}_{1} \mathrm{P}_{2}$ and replace points $\mathrm{P}_{3} \mathrm{P}_{4}$ with all other possible pairs of points and repeat Steps 15 and 16. 
Step 18. Replace points $\mathrm{P}_{1} \mathrm{P}_{2}$ with all other combinations of pairs of points and repeat Steps 15 through 17. From this second survey there will result another tabulation of maximum values.

Step 19. Search the tabulated maximum values from Steps 14 and 18 for the one minimum value and designate it $u_{\min }$. This value is the desired answer for the optimum deviation on the plate. The particular combination that yielded $u_{\min }$ will give the complete set of deviations for the entire surface. 


\section{Least Squares Solution}

A simpler method of establishing a reference plane is by means of a least squares criterion. In this method no search is required since all of the data is used collectively. The criterion involved is that the sum of the squares of the residuals in the $\mathrm{Z}$ direction from all the points be a minimum.

Using the same notation as in preceding sections, the step-by-step procedure is as follows:

Step 1. The X, Y,Z coordinates for all station points are calculated as in Steps 2 through 9 , Section III.

Step 2. Using the coordinates from Step 1, calculate the following summations:

$$
\begin{array}{lll}
\sum \mathrm{x}_{\mathrm{i}}^{2} & \sum \mathrm{y}_{\mathrm{i}}^{2} & \sum\left(\mathrm{y}_{\mathrm{i}} \mathrm{z}_{\mathrm{i}}\right) \\
\sum\left(\mathrm{x}_{\mathrm{i}} \mathrm{y}_{\mathrm{i}}\right) & \sum \mathrm{y}_{\mathrm{i}} & \sum \mathrm{z}_{\mathrm{i}} \\
\sum \mathrm{x}_{\mathrm{i}} & \sum\left(\mathrm{x}_{\mathrm{i}} \mathrm{z}_{\mathrm{i}}\right) &
\end{array}
$$

The summation is carried from one to $\mathrm{N}$, but the index $\mathrm{N}$ is not included in the notation for simplification.

Step 3. Calculate the following constants:

$$
\mathrm{E}=\frac{\left|\begin{array}{lll}
-\sum \mathrm{xz} & \sum \mathrm{xy} & \sum \mathrm{x} \\
-\sum \mathrm{yz} & \sum \mathrm{y}^{2} & \sum \mathrm{y} \\
-\sum \mathrm{z} & \sum \mathrm{y} & \mathrm{N}
\end{array}\right|}{\left|\begin{array}{lll}
\sum \mathrm{x}^{2} & \sum \mathrm{xy} & \sum \mathrm{x} \\
\sum \mathrm{xy} & \sum \mathrm{y}^{2} & \sum \mathrm{y} \\
\sum \mathrm{x} & \sum \mathrm{y} & N
\end{array}\right|}
$$




$$
F=\frac{\left|\begin{array}{lll}
\sum x^{2} & -\sum x z & \sum x \\
\sum x y & -\sum y z & \sum y \\
\sum x & -\sum z & N
\end{array}\right|}{\left|\begin{array}{lll}
\sum x^{2} & \sum x y & \sum x \\
\sum x y & \sum y^{2} & \sum y \\
\sum x & \sum y & N
\end{array}\right|}
$$

$$
G=\frac{\left|\begin{array}{lll}
\sum x^{2} & \sum x y & -\sum x z \\
\sum x y & \sum y^{2} & -\sum y z \\
\sum x & \sum y & -\sum z
\end{array}\right|}{\left|\begin{array}{lll}
\sum x^{2} & \sum x y & \sum x \\
\sum x y & \sum y^{2} & \sum y \\
\sum x & \sum y & N
\end{array}\right|}
$$

The summations are those from Step 2, and the subscript i was intentionally omitted for convenience.

Step 4. Using the constants E,F,G from Step 3, calculate the distance $v_{i}$ from the plane to every station point on the plate by the equation

$$
v_{i}=E_{i}+F y_{i}+G+z_{i}
$$

Select the largest positive value and the largest negative value, disregard signs, and take their sum. This sum is the desired maximum deviation on the plate. The overall contour of the plate is given by the complete set of $v_{i}$ values. If all positive numbers are preferred, this may be achieved by adding the absolute value of the largest negative number to all $v_{i}$ values.

Neither Moody's method nor the least squares solution guarantees optimum results because of the criteria used in establishing the reference planes. A comparison was made between these two methods on ten actual surface plate calibrations. Table 1 shows the maximum deviations as calculated by each method. Positive differences indicate that the Moody's method gives larger values. 
Table 1. Maximum Deviations in Millionths of an Inch for Ten Typical Plates

\begin{tabular}{|c|c|c|}
\hline Moody & Least Squares & Difference \\
\hline 523 & 385 & 138 \\
\hline 592 & 602 & -10 \\
\hline 147 & 126 & 21 \\
\hline 613 & 444 & 169 \\
\hline 112 & 125 & -13 \\
\hline 1175 & 1196 & -21 \\
\hline 220 & 193 & 27 \\
\hline 127 & 140 & -13 \\
\hline 801 & 767 & 34 \\
\hline 190 & 182 & 8 \\
\hline
\end{tabular}

As another comparison, the data from Moody's original paper was processed using the Moody method and using the least squares solution. The deviation calculated using the Moody method was 179 microinches, while the least squares solution gave a deviation of 175.5 microinches. The full results, along with an isometric plot of the least squares results, are included in Figure 2.

Text continued on page 22 . 
SOFTWARE: SURFANAL, 09P-180, VERSION: A, REVISION DATE: $12 / 18 / 96$

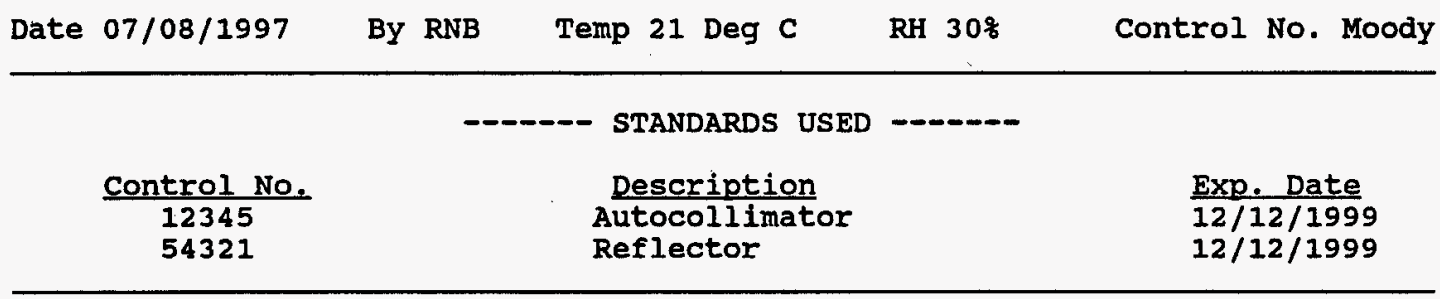

No. Points on Diagonal $=21$

Size $=48 \times 72$

No. Points on North Perimeter $=17$

No. Points on East Perimeter $=11$

Department $=832$

Mirror Footspacing (inches) $=4$

Location $=$

Filename $=$ Moody

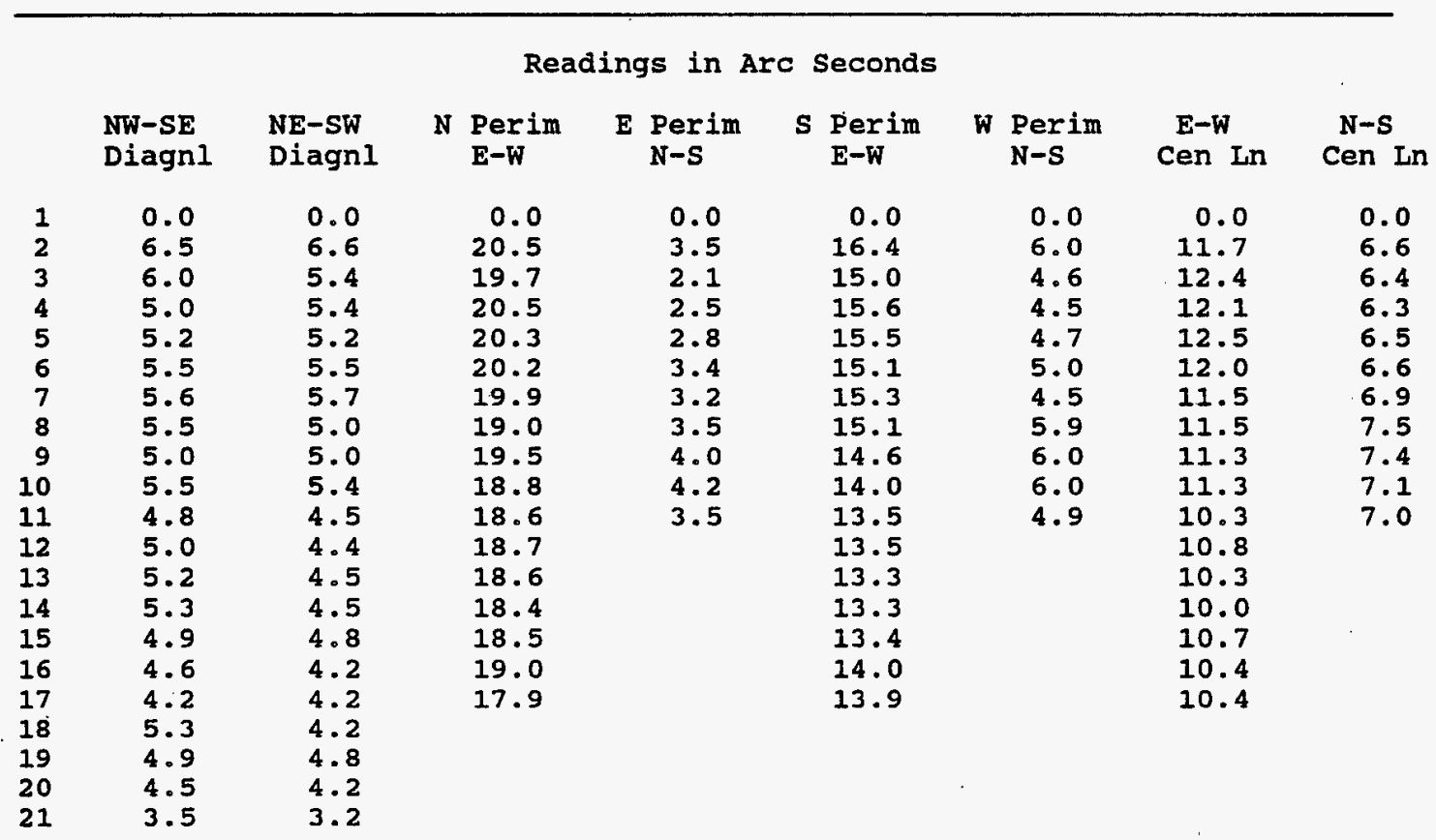

Figure 2. Example Results Using Moody Method and Least Squares Method 
SOFTWARE: SURFANAL, 09P-180, VERSION: A, REVISION DATE: $12 / 18 / 96$ Page 2 of 4 Date 07/08/1997 By RNB Temp 21 Deg C RH 30\% Control No. Moody

Deviations in Microinches using Moody Method

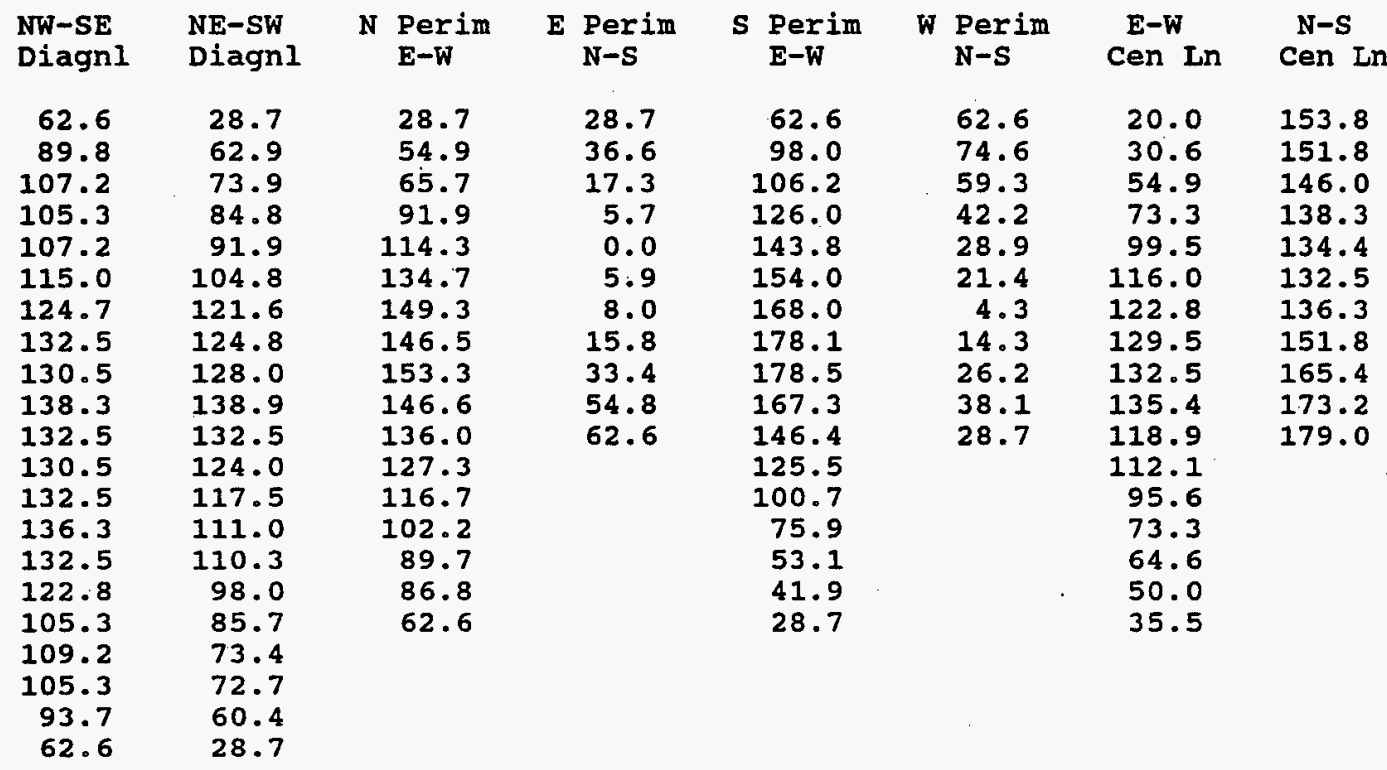

Total Deviation (Moody Method) $=179.0$ Microinches

Closure error on $\mathrm{E}-\mathrm{W}$ Centerline $=14.1$ Microinches

Closure error on $\mathrm{N}-\mathrm{S}$ Centerline $=\quad .5$ Microinches

Figure 2 continued. Example Results Using Moody Method and Least Squares Method 
SOFTWARE: SURFANAL, O9P-180, VERSION: A, REV. DATE: $12 / 18 / 96 \quad$ Page 3 of 4

Date 07/08/1997 By RNB Temp 21 Deg C RH 30\% Control No. Moody

Deviations in Microinches using Least Squares Method

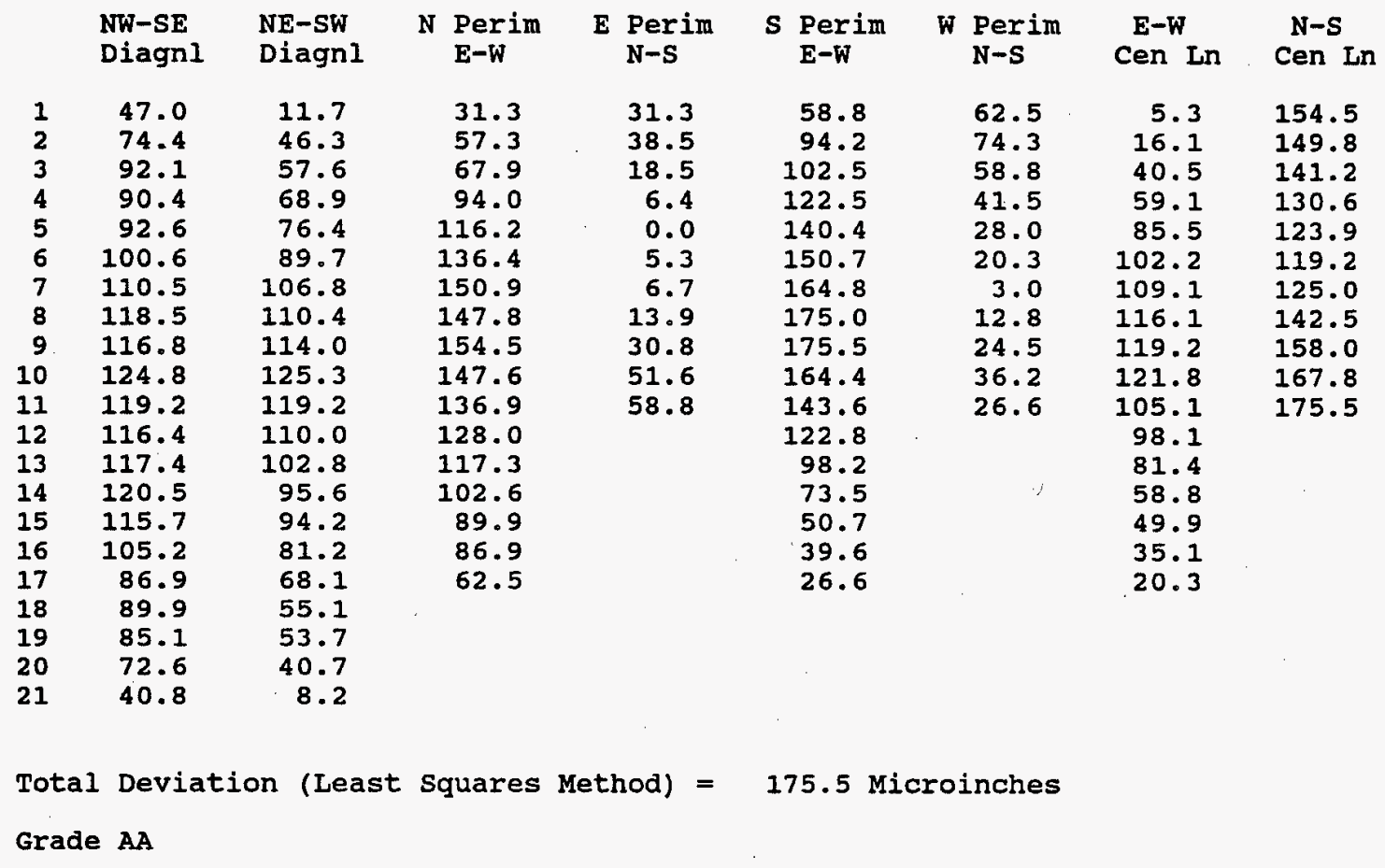

Figure 2 continued. Example Results Using Moody Method and Least Squares Method 
Page 4 of 4

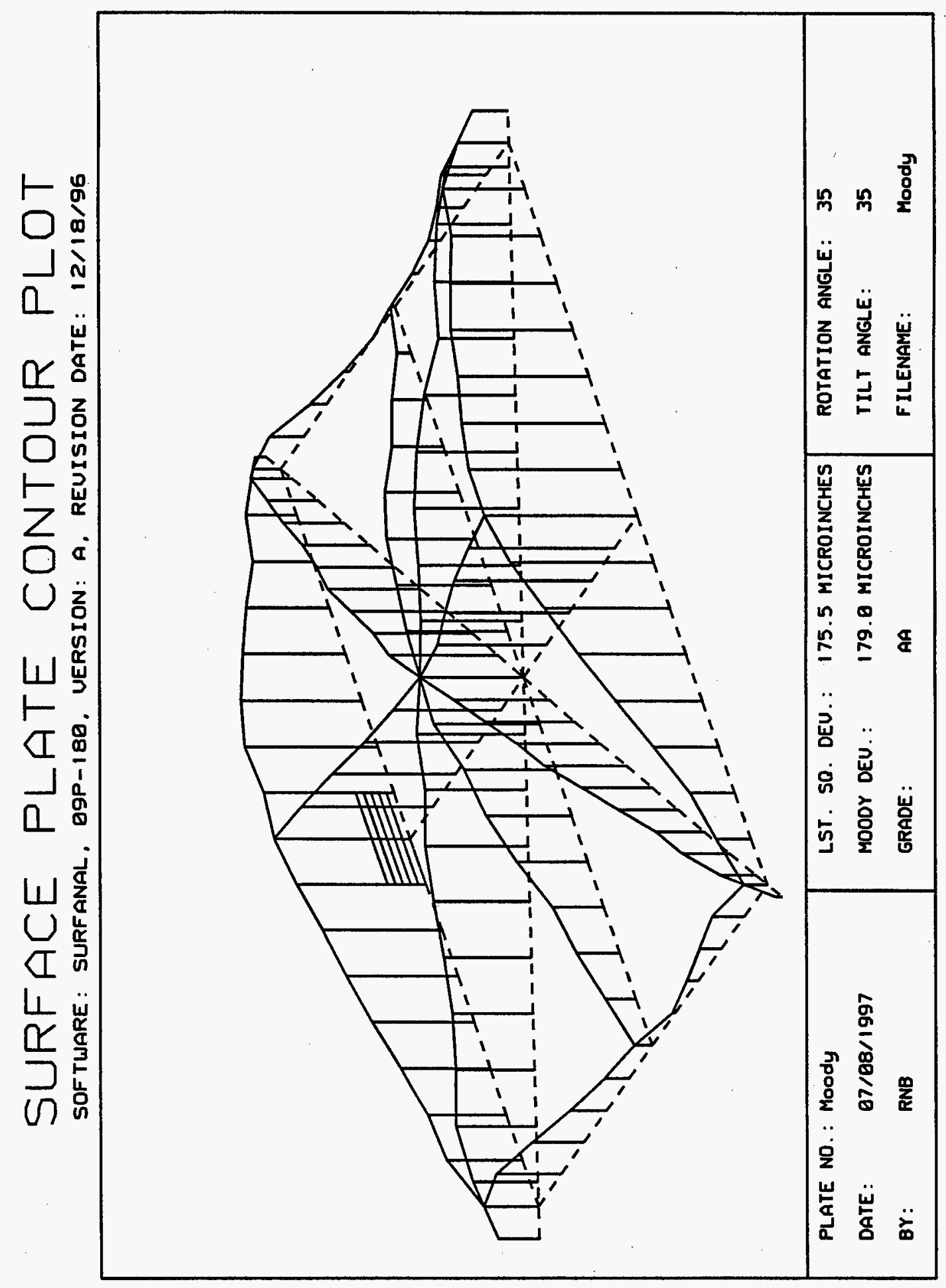

Figure 2 continued. Example Results Using Moody Method and Least Squares Method 


\section{Accomplishments}

The rigorous solution for surface plate calibrations is given in Equations (1) through (49). The method employs the technique of passing parallel planes through all possible combinations of points taken 3 and 1 at a time, and 2 and 2 at a time, and then selecting that one combination giving optimum results.

A simpler solution is offered using the least squares criterion to establish the reference plane. The location of this plane is not optimum, but no search is required since all of the data are used collectively. In comparing the least squares method with the Moody method using data from ten typical plates it was found that the least squares method did not give smaller deviations in all cases. This is to be expected since the location of the reference planes in both methods was chosen on an arbitrary basis. Since the smallest maximum deviation is nearer the optimum value, it is recommended that both methods be used and the plate be assigned the smaller of the two values. 


\section{Reference}

'J. C. Moody, "How to Calibrate Surface Plates in the Plant," The Tool Engineer, October 1955. 


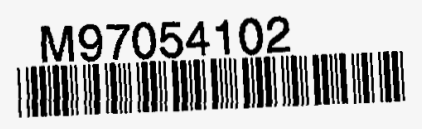

Report Number (14) KCP $-6 / 3-5986$

Publ. Date (11) 199708
Sponsor Code (18)
UC Category (19) $U C-706, D O E / E R$ 